\title{
Conceito e Avaliação de Habilidades e Competência na Educação Médica: Percepções Atuais dos Especialistas
}

\author{
The Concept and Evaluation of Skills and \\ Competence in Medical Education: Current \\ Expert Perspectives
}

Adriana Cavalcanti de Aguiar

Eliana Claudia de Otero Ribeiro ${ }^{I I}$

\section{PALAVRAS-CHAVE \\ - Competência Profissional. \\ - Avaliação Educacional. \\ - Educação Médica.}

Recebido em:21/05/2009

Reencaminhado em: 02/09/2009

Aprovado em: 26/11/2009
The Brazilian National Guidelines for Undergraduate Medical Education foster changes in curricula and the teaching-learning-evaluation processes to develop professional competence and skills. This article is an initiative by the Brazilian Association for Medical Education (ABEM), focusing on the meaning and use of such concepts according to experts in health education evaluation. Ten interviews with open-ended questions were conducted with researchers, selected according to their academic background. Their narratives were submitted to thematic content analysis. The results highlighted the meaning ascribed to competence, the role of subjects involved in the process, the context in which skills and competence are developed, and the relationship between competence assessment in medical education and the provision of comprehensive health care. Although adopting diverse approaches, researchers in the area have embraced the concept of competence creatively. Nevertheless, this study suggests that strengthening a "culture of evaluation" requires investment in study groups and research to deepen the meaning of concepts, objectives, content selection, definition of criteria, development of appropriate tools, and evaluators' training in Brazilian medical schools. 


\section{INTRODUÇÃO}

A homologação, pelo Ministério da Educação (2001), de Diretrizes Curriculares Nacionais (DCN) para os cursos de Medicina orienta a formação para contemplar as necessidades do Sistema Único de Saúde (SUS). Enfatizando o desenvolvimento de competências e habilidades profissionais, as DCN remetem à reflexão sobre a relação teoria-prática na graduação e desafiam as universidades a transformar currículos e processos de ensino-aprendizagem-avaliação. $\mathrm{O}$ presente trabalho é uma iniciativa da Associação Brasileira de Educação Médica para mapear os significados da competência atribuídos por estudiosos do currículo médico e da avaliação educacional, visando compartilhar sua apropriação com a comunidade acadêmica, profissionais de saúde e estudantes, e fomentar o debate, a implementação e a avaliação das DCN.

Tradicionalmente, o modelo de formação médica segue um padrão orientado para o estabelecimento, nos anos iniciais, de uma "base" de conhecimentos teóricos, oriundos das disciplinas biomédicas. Segue-se ao chamado ciclo básico uma sucessão de etapas de ensino-aprendizagem do método clínico, com base no desenvolvimento da semiologia e do raciocínio diagnóstico, em contexto usualmente hospitalar.

Nesse padrão, inspirado no famoso "Relatório Flexner", que em breve completará cem anos, o conhecimento científico transmitido no ciclo básico é descontextualizado e aparece como neutro, numa concepção linear e cumulativa do saber, em analogia a um edifício, em que não se pode supor o teto sem uma base ${ }^{1}$. Schön ${ }^{2}$, no entanto, observa crescentes questionamentos sobre "as ideias hegemônicas de que a pesquisa acadêmica [no caso, biomédica, experimental] rende conhecimento profissional útil, e de que o conhecimento profissional ensinado nas escolas prepara os estudantes para as demandas reais da prática"(p.20). É cada vez mais evidente a distância entre a concepção de conhecimento dominante nas escolas e os atuais requerimentos exigidos para os profissionais nas áreas mais importantes da prática.

Não se trata, obviamente, de desqualificar a pesquisa biomédica, mas, sim, de questionar os modelos de conhecimento implantados institucionalmente nos currículos. No caso da Medicina, é exemplar o reconhecimento da legitimidade profissional decorrente da expertise da prática e não apenas por meio da pesquisa científica. Conhecimentos produzidos pela Epidemiologia (com sua interface com as Ciências Exatas), pela Psicologia, pela Antropologia e pela Comunicação Social (Ciências Sociais e Humanas) também podem ser considerados básicos para a boa prática médica, e a manutenção da atividade profissional concomitante à docência é reconhecida pelos benefícios que traz à formação, e até recentemente a legi- timidade do docente derivava apenas de sua expertise na área de especialidade.

Os padrões acadêmicos, por sua vez, valorizam predominantemente o conhecimento científico disciplinar em detrimento do profissional. As prioridades de investigação não correspondem necessariamente às demandas trazidas do exercício profissional, afastando docentes envolvidos na pesquisa científica e os profissionais clínicos. A seleção e a organização dos currículos são marcadamente influenciadas pela lógica político-institucional na transmissão do conhecimento teórico, impondo importantes desafios pedagógicos para sua articulação com a prática. Prevalece a noção de que o conhecimento profissional rigoroso se baseia na racionalidade técnica e que a formação está orientada para solucionar problemas instrumentais pela aplicação da teoria.

Porém, os problemas da prática, no mundo real, não se apresentam com recortes bem delineados; ao contrário, os problemas se apresentam como cada vez mais complexos e indeterminados. É necessário ensinar os estudantes a tomar decisões sob condições de incerteza, a lidar com a ambiguidade, expondo a fratura entre o mundo real e as práticas academicamente estruturadas ${ }^{3}$. Estas, no caso da saúde, organizam sequências curriculares lineares tradicionais: da forma para a função, do simples para o complexo, do normal para o patológico, da célula para o órgão, do órgão para o sistema, da parte para o todo. A complexidade, a imprevisibilidade, a singularidade e os conflitos de valores escapam à racionalidade técnica. A estrutura institucional da universidade, baseada em departamentos e disciplinas, perpetua a organização do ensino de acordo com os índices de livro-texto das áreas específicas, em flagrante inobservância dos aportes da educação de adultos e dos recursos tecnológicos atualmente disponíveis para a educação.

Tornar-se profissional envolve aprender como manejar situações de forma rápida e eficiente, estabelecendo uma confiança intuitiva em conceitos que ganham sentido na prática ${ }^{4}$. A relevância dos conceitos teóricos decorre menos de sua validade intrínseca do que do intuito e habilidade dos profissionais para utilizá-los. Seu emprego é influenciado pelo contexto de trabalho e pelas formas como o conhecimento é aplicado aos problemas concretos que se apresentam de modos diversos durante a formação e a prática.

A melhor articulação entre teoria e prática na formação depende da construção coletiva de um saber sobre o que constitui o conhecimento profissional e de como os profissionais aprendem e desenvolvem sua expertise. Implica estabelecer relações entre a produção de vários tipos de conhecimento, seu uso no contexto profissional e a educação permanente, uma tríade articulada tanto no contexto acadêmico quanto no profissional ${ }^{5,6}$. 
Os diferentes contextos organizacionais em que as práticas ocorrem afetam o tipo de conhecimento e suas formas de utilização. Estudos sobre aprendizagem de adultos ${ }^{7}$ informam que, para que uma ideia ou conceito seja integrado, é necessário que esteja contextualizado, ajustado à especificidade do meio no qual o sujeito interage, processo que incide sobre a base pessoal do conhecimento ${ }^{5}$. A ideia prevalente de que primeiro aprendemos o conhecimento para depois aplicá-lo é questionada na medida em que a contextualização intrínseca à aplicação já transforma o conhecimento. Assim, ser capaz de aplicar um conhecimento em um contexto não significa necessariamente sê-lo em outro; ao contrário, cada contexto significa uma aprendizagem, e em cada experiência transformam-se também as ideias e os sujeitos $^{8}$.

Embora o sentido da terminalidade da graduação venha sendo progressivamente questionado ${ }^{9}$, persiste a visão de que esta deve fornecer o conhecimento necessário para toda a vida profissional, o que é utilizado como justificativa para uma inflação de conhecimentos teóricos, transmitidos e avaliados independentemente da capacidade de absorção e fixação pelos alunos. Reconhecer a necessidade de formar profissionais preparados para a constante mudança das bases materiais e cognitivas de seu trabalho, e para enfrentar novas demandas da sociedade, facilitaria a compreensão de que a formação deve assentar-se desde o início em práticas em contextos reais, articuladas com a educação permanente e continuada de profissionais formados e em pleno exercício profissional.

Essa reflexão fundamenta a incorporação de "novos cenários" de ensino-aprendizagem no percurso dos alunos, no que diz respeito tanto à relação teoria-prática em contextos tradicionais acadêmicos, quanto às experiências inovadoras de articulação de saberes disciplinares nas práticas de ensino orientadas por problemas. Como lembra Pestana ${ }^{10}$ :

A compreensão da competência como capacidades, estilos de desempenho ou modelos de comportamento de um sujeito não situado significa a negação da dimensão social e relacional da competência. Mesmo assim, a atuação dos sujeitos nas situações em que a competência é requerida só se dá de forma contextualizada, historicamente referida. (p. 64)

Em suma, os conhecimentos sistematizados no âmbito escolar são contextualizados para uso no meio acadêmico, e seu emprego em outros ambientes (de prestação de serviços, por exemplo) implica sua reelaboração por docentes e alunos. O trabalho nos contextos reais de prática profissional envolve muitas dimensões além do conhecimento teórico, em geral implícitas nas rotinas e relações estabelecidas entre os agentes do cuidado. Esse outro conhecimento, tácito, construído empiricamente com base na experiência, é mais difícil de ser transformado do que o conhecimento sistematizado e, apesar de sua importância, não tem o mesmo status do conhecimento técnico ${ }^{11}$. Relegado a compor o chamado "currículo oculto"12, tem inegável impacto no ensino de atitudes profissionais, mas escapa da problematização que deve pautar o desenvolvimento curricular na área da saúde. A visão dominante subestima a capacidade dos sujeitos de interpretar, refinar e transformar a prática. Sem ocupar um lugar ativo na própria formação, os alunos não valorizam seu saber. Se tiverem a oportunidade de enfrentar situações reais da prática, podem identificar novas formas de abordar a realidade, estabelecer e testar categorias de compreensão e estratégias de ação.

\section{O Conceito de Competência}

Entendida nas DCN como um dos eixos que orientam a mudança no ensino e avaliação da aprendizagem, no nível estratégico a noção de competência vem provocando discussão entre diferentes atores sobre as relações da escola com o mundo do trabalho. Requer ser explorada em seus limites ainda imprecisos e em suas possibilidades de apreensão. Nos campos cada vez mais próximos da educação e do trabalho, tende a substituir velhas noções de saberes, conhecimentos e de qualificação. Por seu caráter polimorfo, favorece seu uso em situações variadas, por agentes com interesses diversos.

Distinguem-se, no senso comum, duas noções prevalentes de competência: (i) a legitimidade de uma pessoa ou instância para julgar ou decidir sobre um fato (por exemplo, ao mencionar a competência do âmbito municipal no contexto da descentralização das ações de saúde) e (ii) as capacidades reconhecidas de um sujeito, numa dada matéria, e vinculadas à sua expertise e conhecimentos ${ }^{13}$. Em sua gênese, o termo competência colocava em relação (numa dada população que desenvolvesse atividades socialmente organizadas) os indivíduos (ou instâncias) e as tarefas que lhes fossem atribuídas, sendo tal atribuição decorrente do reconhecimento de seu direito ou saber. A acepção, atualmente prevalente, de competência como capacidade do indivíduo representa, ao mesmo tempo, a permanência e a evolução do significado original. Preserva a ligação distintiva entre o indivíduo e a tarefa num dado grupo social, mas desloca seu sentido para o conteúdo psicocognitivo da competência, minimizando sua característica de relatividade social ${ }^{13}$.

Frequentemente, na Pedagogia, a noção de ensino baseado em competência foi associada à avaliação de objetivos comportamentais. É o caso da aprendizagem pelo domínio, pro- 
posta por Bloom et al. ${ }^{14}$. O objetivo do ensino (portanto, o que merece ser avaliado) também adotou o conceito de performance ou desempenho, ou seja as ações efetivamente manifestas ${ }^{15}$ : um objetivo útil explicitaria as condições nas quais o estudante deveria realizar dado desempenho, definindo o nível de performance considerado aceitável. Aprofundando a reflexão sobre as consequências de identificar comportamento com o próprio domínio do saber que o estrutura, $\operatorname{Ramos}^{15}$ faz uma interessante crítica ao percurso da Pedagogia neste campo.

Na prática, como a conceitualização pedagógica sobre o desenvolvimento de competências tem raízes no comportamentalismo (behaviorismo), muito influente na psicologia e na educação nos anos 1960 e 70, sua apropriação (ainda marcante na formação de técnicos de nível médio) traduz-se pela utilização de listas de tarefas e subtarefas, cuja realização é verificada mediante check lists. A substituição da noção de comportamento, tradicionalmente identificada como conteúdo manifesto da capacidade, pela de competência enseja uma concepção de desempenho como conjunto de atributos e capacidades mobilizados pelo sujeito na ação. Perrenoud ${ }^{16}$ alerta que o uso corrente da noção de competência não significa a superação da ênfase na definição de objetivos (comportamentais). Frequentemente, usam-se "competências" para expressar objetivos de ensino em termos de condutas e práticas observáveis, acrescentando um "ser capaz de", uma expressão que caracteriza uma ação, sem maior preocupação com a necessidade de transferência de conhecimentos para aplicação em contextos diversos ou sua mobilização em situações complexas.

A associação "de uma competência a um simples objetivo de aprendizado confunde as coisas e sugere, erradamente, que cada aquisição escolar verificável é uma competência"16 (p.18). Essa abordagem se apoia na premissa de que há sempre uma "melhor maneira" de realizar as tarefas. Existe, entretanto, uma outra compreensão sobre competência, que trabalha com o desenvolvimento de atributos (cognitivos, psicomotores e afetivos) que, combinados, ensejam distintas maneiras de realizar, com sucesso, tarefas essenciais e características de determinada prática profissional. Assim, diferentes combinações podem compor os padrões de excelência que regem a prática profissional, permitindo que sujeitos desenvolvam um estilo próprio, adequado e eficaz para enfrentar situações profissionais (familiares ou não). Essa abordagem, considerada holística, precisa ser desenvolvida em articulação com o mundo do trabalho, onde as práticas são desenvolvidas ${ }^{8,17}$.

Sendo assim, a competência não é algo que se observe diretamente, mas pode ser inferida pelo desempenho. Este, na perspectiva construtivista, não se restringe à execução de uma série de tarefas discretas, definidas de modo meramente técnico e avaliadas por uma abordagem descontextualizada (por exemplo, mediante a aplicação de um check list). Esta abordagem simplista subestima o desenvolvimento (e a avaliação) dos atributos que subjazem aos desempenhos e os fundamentam, reduzindo a aprendizagem ao cumprimento de tarefas atomizadas.

Em sua função de qualificação social, a noção de competência associa a abordagem "cognitivista" da competência, descrita acima, à dimensão de construção da identidade do sujeito como ator social, que se transforma ao longo da sua trajetória de aquisições profissionais ${ }^{13}$. Esta abordagem, de natureza construtivista, enfatiza a historicidade dos sujeitos e seu papel nas mudanças institucionais e sociais (fundamentais para a plena implantação do SUS, por exemplo). Em outras palavras, a concepção construtivista de competência incorpora formas e meios pelos quais o sujeito, ao se apropriar de sua profissão ou ocupação, contribui para reproduzir ou transformar esta mesma ocupação ou profissão. Contrapõe-se assim às visões que percebem a aprendizagem como adaptação dos indivíduos a uma ocupação constituída (concepção condutivista).

As matrizes referenciais para as diferenças encontradas nos conceitos de competência têm raízes histórico-sociais nos países onde foram desenvolvidas e representam disputas ideológicas no campo da educação. A definição de currículos baseados em competência requer uma opção conceitual em relação ao entendimento da competência como resultante da relação entre o mundo de aprendizagem e o mundo do trabalho. A articulação de tarefas e capacidades verificáveis pelo desempenho (entendido aqui de maneira mais ampliada) permitiria a inferência de competência para determinada área profissional a partir de padrões ou critérios pactuados, considerados necessários e desejáveis para a transformação das práticas em saúde ${ }^{8,17}$.

Este estudo, solicitado pela diretoria da Associação Brasileira de Educação Médica, além de problematizar a apropriação da noção de competência realizada pelos estudiosos da avaliação educacional na medicina brasileira, quis investigar sua relação com a construção da integralidade em saúde. Este outro termo polissêmico é passível de controvérsia ${ }^{18,19}$, mas tem permeado o debate sobre formação e prática em saúde. Assim, situa-se no bojo das iniciativas que visam fomentar a desconstrução e reconstrução das concepções vigentes de saúde-doença-cuidado e ensino-aprendizagem-avaliação.

\section{OBJETIVO E MÉTODOS}

O estudo buscou compreender a percepção de especialistas em educação médica sobre o conceito de competência e suas consequências para a formação profissional no contexto da implantação das DCN. Foram realizadas dez entrevistas, com respostas escritas mediante roteiro com oito questões abertas. 
Os respondentes compõem uma amostra intencional ${ }^{20}$ de professores com produção acadêmica sobre avaliação educacional na medicina e que são colaboradores habituais das iniciativas da Abem, participando, inclusive, de seus congressos. Todos têm doutorado, sete são do sexo feminino e três são homens. A maioria atua em instituições públicas, exceto uma pessoa. Todos estão filiados a instituições sediadas nas regiões Sul e Sudeste, com inserção em cursos de graduação em Medicina e também na pós-graduação stricto sensu.

O material obtido nas entrevistas foi submetido a análise de conteúdo, que intenta superar a descrição dos conteúdos manifestos e, por meio de uma postura interpretativa, ir além do enunciado, desvelando as condições de sua produção, em um quadro de referência do contexto social no qual as mensagens se inserem. A técnica empregada foi a análise temática, que "consiste em descobrir os 'núcleos de sentido' que compõem a comunicação e cuja presença ou frequência de aparição podem significar algo para o objetivo analítico escolhido"21 (p.105). A técnica utiliza como unidade de registro o tema, que corresponde a uma regra de recorte do sentido (e não da forma), isto é, pode ter extensão variável, constituindo uma afirmação ou várias, às vezes num pequeno fragmento. “O tema é a unidade de significação que se liberta naturalmente de um texto analisado segundo certos critérios relativos à teoria que serve de guia à leitura"21 (p.105). O texto das entrevistas foi lido diversas vezes na fase de pré-análise (leitura flutuante) até a obtenção de uma visão de conjunto do material e a apreensão de suas particularidades. Então, os temas foram distribuídos segundo uma classificação inicial, que deu origem a eixos temáticos num processo progressivo de categorização.

\section{RESULTADOS}

\section{Os Significados do Conceito de Competência}

A análise dos núcleos de sentido das entrevistas com docentes levou à construção de três categorias que perpassam a construção dos significados sobre o conceito de competência: a hierarquia entre habilidades e competências, os sujeitos da construção da competência e a influência do contexto na construção da competência.

É possível identificar entre os entrevistados duas entre as três visões sobre competência discutidas no referencial teórico apresentado acima e do qual foram extraídas as categorias analíticas aqui utilizadas. Nesse sentido, as habilidades são compreendidas como:

(a) parte constituinte ou conteúdo da competência que acaba, assim, por estar definida como conjunto de atributos de natureza cognitiva, psicomotora e afetiva, também qualificados como dimensões da competência ("As capacidades que compõem uma competência...");

(b) atributos mobilizados na ação, referente à natureza dos problemas/tarefas que o profissional enfrenta em seu campo de trabalho, definição pela qual a competência é algo abstrato, podendo apenas ser inferida pelo desempenho: "Competência é uma síntese, uma abstração que só pode ser verificável pela observação da prática profissional (ações fundamentadas e contextualizadas)".

Em outras palavras, os entrevistados adotam uma concepção de competência que supera a mera execução de tarefas, o simples fazer. Nos relatos que consideram a competência como conjunto de habilidades, os entrevistados distinguem as duas noções, e aparece de forma interessante um núcleo de sentido que expressa uma hierarquia entre estas: "a competência tem maior abrangência", ou ainda, "a diferença é de nível hierárquico, visto que entendo competência como um conjunto de habilidades de naturezas diversas". A imagem do volume ou tamanho também denota esta hierarquia: "a extensão do termo competência é mais ampla, apesar de esses termos serem usados indiferentemente", ou ainda "a diferença caracteriza-se pela extensão que tem sido dada a esses termos".

Tal noção hierárquica também aparece na análise das respostas relativas à avaliação da competência, nas quais emerge reiteradamente a imagem da Pirâmide de Miller ${ }^{22}$. Esta figura, bastante conhecida, apresenta uma ampla base (o saber), sobre a qual repousam o saber fazer, o mostrar como fazer e, por último, o fazer. O topo da pirâmide é identificado como a competência, e o "mostrar como" é associado à habilidade. Notam-se, portanto, em algumas entrevistas, remanescentes da concepção comportamentalista de competência, alicerçada na visão estrutural do conhecimento, representada pelo saber da base. Ainda que a Pirâmide de Miller ajude a estabelecer as diferenças entre a avaliação de atributos (cognitivos, habilidades diversas) e de desempenho, sua estrutura gráfica reforça a hierarquia acima aludida, excluindo as relações dinâmicas entre conhecimento (base) e ação (topo). A pirâmide, assentada no conhecimento existente, poderia estruturar-se, nesta visão, sem implicar a construção do conhecimento na ação.

Por outro lado, algumas respostas referentes à avaliação da competência deixaram emergir um núcleo de sentido que articula construção da competência com processos de avaliação formativa (com o apoio de multimétodos). Esta inclui diferentes sujeitos (pares, docentes, o próprio aluno e os pacientes), assumindo que estes terão diferentes olhares sobre o objeto avaliado. Nas palavras de um entrevistado: “a avaliação de desem- 
penhos reflete claramente o modelo de cuidado priorizado; a pactuação de critérios de avaliação é um momento de reflexão relevante para reavaliação de práticas profissionais". Essa ótica aponta para maior valorização da concepção construtivista, sendo coerente com as narrativas que enfatizam a importância do contexto e dos sujeitos na ação. Destacam-se elementos de valor, conferido por alguns dos entrevistados, às dimensões técnica, política e ética, envolvidas na prática profissional e ligadas ao processo de construção de competência. Os entrevistados fazem referência à competência como "mais do que habilidade de resolver problemas, é a capacidade de lidar e tomar decisões no manejo de problemas complexos", envolvendo o contexto, sujeitos, subjetividades e valores. Essas considerações denotam o reconhecimento, por alguns dos entrevistados, do contexto social da ação envolvida na construção da competência:

a competência é sempre referente a um sujeito e, portanto, deve-se levar em conta que esta tem a ação como objeto, em determinado contexto. [...] Não deve se restringir a um simples saber-fazer, para que não resulte numa prática burocrática, automatizada, que exclua a subjetividade, reflexão e criatividade daquele que a realiza.

Ainda sob essa mesma abordagem, tratando-se de competências profissionais, foi citado que o processo de ensino-aprendizagem precisa ocorrer nos ambientes de trabalho, o que implicaria atividades multiprofissionais e conhecimentos interdisciplinares. Destaca-se, aqui, o reconhecimento pelos entrevistados da importância da diversidade de experiências e cenários na construção da competência. Mais uma vez, expressam uma concepção de competência que não a resume a um conjunto de habilidades que poderiam ser construídas sem a dimensão de contexto

Chama a atenção o fato de que, na análise das narrativas sobre avaliação, alguns elementos que emergem não guardam, necessariamente, coerência com as noções de competência apresentadas. A hipótese, a ser mais bem investigada, é que o conceito de desempenho, central sob a perspectiva da avaliação de competência, reteve uma faceta comportamental (dissociada do contexto social da ação), mas caminha em paralelo à construção, em âmbito coletivo, de uma visão de avaliação mais elaborada, que incorpora a importância das diferenças de valores e atribui aos sujeitos da avaliação papel de destaque.

\section{Ensino-aprendizagem e Avaliação de Competência e a Construção da Integralidade em Saúde}

O estudo buscou articular o debate sobre competência com aquele relativo à construção da integralidade na formação e na prática em saúde. A análise dos resultados utilizou duas dimensões da integralidade assinalados por Mattos ${ }^{19}$ : competência e integralidade aparecem subjacentes às práticas profissionais e à organização dos serviços. Para um dos entrevistados:

\footnotetext{
É preciso que a integralidade da atenção esteja compreendida entre os objetivos do currículo, que no processo de ensino-aprendizagem as capacidades que compõem esta competência estejam bem definidas, que os cenários de prática privilegiem a vivência com o paciente, a comunidade, a realidade social. Neste caso, as estratégias de avaliação formativa, desenhadas para permitir a reflexão sobre a ação, vão poder integrar a aquisição da competência.
}

Outro entrevistado enfatiza a dimensão educativa da competência, associada potencialmente à integração entre prevenção e tratamento: visaria à "construção do sujeito, via esfera educativa, na qual estariam presentes as dimensões técnica, política, ética e estética, que incluem um pensamento crítico". Atitude, emoção e aprendizagem são também articuladas: "a integralidade na atenção resgata a concepção do cuidado, no qual as diferentes dimensões da aprendizagem precisam ser contempladas: a teórico-conceitual, a psicomotora e a afetiva. Não é possível uma integralidade na atenção separando estas partes". Um dos respondentes citou Epstein e Hundert ${ }^{23}$ para definir competência de modo abrangente, análogo a componentes do debate sobre integralidade: "uso habitual e criterioso da comunicação, conhecimento, habilidades técnicas, raciocínio clínico, emoções, valores e capacidade de refletir sobre a prática diária para o benefício do indivíduo e comunidade que está sendo atendida" (p. 226, tradução nossa).

Uma entrevistada associa duas dimensões da integralidade com a competência: "comunicar-se efetivamente com pacientes e colegas (função relacional) e usar estas habilidades de forma criteriosa e humana com vontade, paciência, de forma consciente (função afetivo/moral)", abarcando a relação com pares e colegas de equipe (o que, segundo Mattos, abrangeria a dimensão da integralidade como organização da prestação de serviços).

Esta dimensão da integralidade está afeita à problematização da relação teoria-prática. Foi lembrado que:

$\mathrm{O}$ processo de ensino-aprendizagem deve estar inserido no mundo do trabalho. Além dos cenários, os professores (orientadores, tutores, supervisores, profissionais de serviço) deverão estar capacitados para o ensino e avaliação de habilidades e competências, para 
o trabalho interdisciplinar [...] Um dos princípios da organização curricular recomendado pelas diretrizes é a articulação teórico-prática e a ação nos diversos níveis de atenção, fundamentais para o desenvolvimento almejado.

Além da interdisciplinaridade, outro componente intrínseco da organização de serviços na construção da integralidade apareceu nas narrativas: o trabalho em equipe e a multiprofissionalidade: "A integralidade na atenção também implica o desenvolvimento da habilidade para o trabalho em equipe, muito pouco contemplada nos nossos processos formativos".

Não apenas a aprendizagem, mas também sua avaliação irá fomentar (ou não) o desenvolvimento de competência que promovam a integralidade na atenção à saúde.

Precisa existir uma coerência entre o currículo e avaliação. [...] todo o processo, desde a elaboração das questões e aplicação destas questões teóricas, práticas ou teórico-práticas, vai sempre remeter o estudante para a realidade de saúde e a como enfrentar os principais problemas de saúde, contribuindo para a integralidade.

Em síntese, as relações entre ensino-aprendizagem, avaliação de competência e construção da integralidade que emergiram nas entrevistas associam desenvolvimento de competência com a concepção ampliada de saúde e a compreensão da indissociabilidade entre indivíduo/sujeito e suas relações sociais: "a integralidade na atenção implica o desenvolvimento das diferentes habilidades que garantem determinada competência". Em congruência com os achados anteriormente relatados, esta visão é também perpassada pela noção de competência como soma de atributos.

\section{CONSIDERAÇÕES FINAIS}

Embora desperte controvérsia, o conceito de competência tem sido apropriado de modo fértil na discussão sobre mudanças na formação em saúde. Ao recolocar a prática profissional no foco, ajuda a pressionar as escolas a repensar seus currículos e processos avaliativos, reorientando o planejamento educacional a partir do perfil de competência desejável para seus egressos.

Usualmente, abordam-se conhecimentos, habilidades e atitudes como entidades diferentes e separadas, reduzindo o conhecimento apenas à sua dimensão teórica, proposicional. Separam-se teoria e prática, conhecimento sistematizado e pessoal, pensamento intuitivo e analítico. Incluir a dimensão do significado atribuído pelo sujeito implica admitir que o conhecimento não pode ser caracterizado de forma independen- te de como foi aprendido e de como é usado, ou seja, o contexto da aquisição e o de seu uso são fundamentais para revelar a natureza do conhecimento.

Mesmo considerando o papel que o conhecimento científico publicado e sistematizado exerce no desenvolvimento do conhecimento profissional, educadores médicos experientes aqui entrevistados reconhecem que este também é construído por meio da experiência e que sua natureza depende das formas de aquisição e de interpretação dessa experiência. O saber se elabora segundo uma ordem pessoal e a partir da experiência de cada um, é gerado e compartilhado culturalmente e está em constante transformação.

Além disto, não se avalia competência, avaliam-se desempenhos que traduzem a ação profissional considerada competente. Por meio dos desempenhos infere-se a competência. Capacidades podem ser avaliadas por meio de situações simuladas e/ou práticas profissionais em contextos reais não simulados. A melhor forma de avaliar desempenho é definir a tarefa a ser realizada em dado contexto e verificar a capacidade do aluno de, naquela situação particular, mobilizar seus atributos de forma adequada para realizar a tarefa. A competência é aprimorada, no dia a dia, no processo de ensino-aprendizagem e na vivência do sujeito, na qual ele sofistica seu conhecimento tácito.

Percebe-se uma apropriação heterogênea dos conceitos de competência e habilidades pelos representantes da comunidade acadêmica brasileira no momento atual. Os resultados apontam percepções distintas, mas em geral os entrevistados estão atentos à polifonia intrínseca ao conceito de competência(s). O estudo sugere que a consolidação de uma "cultura de avaliação" nas escolas médicas que supere uma apropriação meramente punitiva demandará investimentos em núcleos de estudo e pesquisa (já presentes em algumas instituições de ensino superior), para aprofundamento de conceitos, objetivos, seleção de conteúdos, pactuação de critérios, elaboração de instrumentos e treinamento de avaliadores nas instituições brasileiras. A democratização desse conhecimento é fundamental para a reorientação do ensino e avaliação na direção do perfil proposto pelas Diretrizes Curriculares para os egressos.

\section{REFERÊNCIAS}

1. Barth BM. Le savoir en construction: former à une pédagogie de la compréhension. Paris: Retz; 1994.

2. Schön D. Educando o profissional reflexivo: um novo design para o ensino e a aprendizagem. Porto Alegre: Artmed; 2000.

3. Pierantoni CR, Ribeiro ECO. A Importância do processo de Educação Permanente na formação do médico: o do- 
cente como inovador/mediador/indutor de condições de auto-aprendizagem. In: Arruda BKG, org. A Educação Profissional em Saúde e a Realidade Social. Recife: Instituto Materno-Infantil de Pernambuco/ Ministério da Saúde; 2001. p.179-200.

4. Eraut M. Developing professional knowledge and competence. London: The Falmer Press; 1994.

5. Ribeiro EC, Motta JI. Educação Permanente como Estratégia na Reorganização dos Serviços de Saúde. Divulg Saúde Debate. 1996, (12):39-44.

6. Aguiar AC. A Pesquisa e a Educação Médica no Brasil Hoje: reflexões sobre Metodologia e Estratégias. In: Marins JJN, Rego S, Lampert JB, Araújo JG, orgs. Educação Médica em transformação: instrumentos para a construção de novas realidades. São Paulo: hucitec; Rio de Janeiro:Abem; 2004. p.304-24.

7. Moreira MA. Aprendizagem Significativa. Brasília: Ed. UnB;1999.

8. Ribeiro ECO. Representações de alunos e docentes sobre as práticas de cuidado e de formação: uma avaliação de experiências de mudança em escolas médicas. Rio de Janeiro; 2003. Doutorado [Tese] — Universidade do Estado do Rio de Janeiro.

9. Vaz P. Perspectivas da formação profissional do século XXI. Caderno CE. 2000;1(1):9-12.

10. Pestana MIGS. A Polissemia da Noção de Competência: Uma Análise do Discurso do Setor Público sobre Gestão, Avaliação e Certificação de Competências. São Paulo; 2006. Mestrado [Dissertação] — Pontifícia Universidade Católica.

11. Penaforte J. John Dewey e as raízes filosóficas da aprendizagem baseada em problemas. In: Mamede S, Penaforte J, Schmidt H, Caprara A, Tomaz JB, Sá H, orgs. Aprendizagem Baseada em Problemas: anatomia de uma nova abordagem educacional. Fortaleza: Escola de Saúde Pública do Ceará; São Paulo:Hucitec; 2001. p. 49-79.

12. Sacristán JG. El Curriculum: una reflexión sobre la práctica. Madrid: Ediciones Morata; 1991.

13. Hillau B. De l'intelligence operatoire à l'historicité du sujet. In: Minet F, Parlier M, Witte S. La compétence, mythe, construction ou réalité? Paris: Éditions l’Harmattan; 1994.
14. Bloom B, Krathwohl DR, Masia BB. Taxionomia de Objetivos Educacionais. Compêndio segundo: domínio afetivo. Porto Alegre: Editora Globo; 1973.

15. Ramos MN. A Pedagogia das Competências: autonomia ou adaptação? São Paulo: Cortez; 2001.

16. Perrenoud P. Construir as competências desde a escola. Porto Alegre: Artmed; 1999

17. Lima VV. Avaliação de Competência nos Cursos Médicos. In: Marins JJN, Rego S, Lampert JB, Araújo JG, orgs. Educação Médica em Transformação: instrumentos para a construção de novas realidades. São Paulo: Hucitec; Rio de Janeiro:Abem; 2004. p.123-40.

18. Mattos RA. Os sentidos da Integralidade: algumas reflexões acerca de valores que merecem ser defindidos. In: Pinheiro R, Mattos RA, orgs. Os sentidos da Integralidade na atenção e no cuidado á saúde. Rio de Janeiro: IMS,ABRASCO; 2001. p. 39-64.

19. Camargo Júnior KR. Biomedicina, Saber e Ciência: uma abordagem crítica. São Paulo: Hucitec; 2003.

20. Maxwell JA. Qualitative Research Design: an Interactive Approach. Thousand Oaks: Sage book; 1996.

21. Bardin L. Análise de Conteúdo. Lisboa: Edições 70; 1977.

22. Miller GE. The assessment of clinical skills/competence/ performance. Acad Med. 1990;65 (Suppl 9):63-7.

23. Epstein RM, Hundert EM. Defining and Assessing Professional Competence. JAMA 2002; 287: 226-35.

\section{CONTRIBUIÇÃO DOS AUTORES}

Adriana Aguiar contribuiu na concepção, desenho, coleta e análise de dados do artigo. Eliana Claudia contribuiu no desenho, coleta e análise de dados e redação do artigo.

\section{CONFLITO DE INTERESSES}

Declarou não haver.

\section{ENDEREÇO PARA CORRESPONDÊNCIA}

Adriana Cavalcanti de Aguiar

Rua do Riachuelo, 27 - 6o andar

Centro - Rio de Janeiro

CEP 20230-010

E-mail: aguiaradri@gmail.com 